\title{
Pretreatment Reproductive Stage and Oocyte Development Induced by Salmon Pituitary Homogenate in the Japanese Eel Anguilla japonica
}

\author{
Shigeho Ijiri, ${ }^{* 1, \dagger}$ Takaaki Kayaba, ${ }^{* 1}$ Noriko Takeda, ${ }^{* 1}$ \\ Hiroyuki Tachiki, ${ }^{* 2}$ Shinji Adachi, ${ }^{* 1}$ and Kohei Yamauchi*1 \\ ${ }^{*}$ Department of Biology, Faculty of Fisheries, Hokkaido University, Hakodate 041-8611, Japan \\ ${ }^{* 2}$ Aichi Fish Farming Institute, Atsumicyo, Atsumi, Aichi 441-3615, Japan
}

(Received December 24, 1997)

Induction of the ovarian development was investigated in three groups of eels with respect to the importance of the pretreatment reproductive stage. Initially, the developmental stages of oocytes varied widely among these groups; silver eels had the most advanced oocytes which were in the early stage of vitellogenic growth, whereas oocytes from feminized eels were in the oil droplet or early vitellogenic stage and those from cultivated eels were in the oil droplet stage.

Eels received weekly intramuscular injections of salmon pituitary homogenate (SPH) at $20 \mu \mathrm{g}$ per g body weight (low-dose treatment). The ovarian follicles of silver eels developed the fastest and reached the final maturational stage after, on average, 10 weeks of treatment. The oocytes of feminized eels and cultivated eels developed more slowly, requiring approximetely 17 and 19 weeks of treatment, respectively. All silver eels were induced to the final maturational phase $(100 \%)$, but lower ratios were seen for feminized and cultivated eels ( 64 and $29 \%$, respectively).

Feminized eels were also subjected to a high-dose treatment of SPH ( $40 \mu \mathrm{g}$ per g body weight). High-dose treated feminized eels were induced to the final maturational phase in less time (11 weeks) and with greater efficiency $(71 \%)$ than low dose-treated feminized eels. It was shown that eels whose follicle diameter was over about $180 \mu \mathrm{m}$ could be stimulated to develop through the final maturational phase. This result indicates that the majority of feminized eels may be expected to reach the final maturational phase after SPH treatment. However, a $100 \%$ rate to reach the final maturational phase could not be attained, possibly due to immunoreaction to SPH, the stress of injections, or other yet unidentified factors.

We conclude that silver eels are the best candidates for artificial maturation. Even though feminized eels were not the most responsive group, their abundance makes them an important resource. Moreover, we recommend that eels should be induced to the final maturational phase during a relatively short period of SPH treatment (about two to three months) for artificial maturation to be successful.

Key words: Japanese eel, feminized eel, artificial maturation, ovary, gonadosomatic index

The Japanese eel Anguilla japonica, is a commercially important species in the aquaculture industry of Japan. The life history of this fish is complex, and little is known about its reproduction as sexually mature eels have never been found in the wild. At present, elvers for stocking of farms are obtained from the wild. However, the catch of elvers has recently decreased, which may pose serious problems for obtaining elvers for aquaculture. Therefore, it is important that a reliable supply of larvae is established. In this context, artificial control of gonadal development is essential for obtaining captive-bred eel larvae.

Sexual development in Japanese eels is initiated at the silver stage, when the catadromous migration begins in autumn or early winter, at the age of 5-12 years. However, they do not undergo further gonadal development and vitellogenic growth under aquarium conditions. Thus, hormonal treatment is necessary to induce advanced stages of sexual development in captive eels.
Since the 1940's many studies have been performed with the aim to induce ovarian growth and maturation using silver eels. ${ }^{1)}$ In the silver Japanese eel, artificial maturation by repeated injections of salmon pituitary homogenate (SPH) was started in the 1970's. Using this method, fertilized eggs were obtained, and hatching of eggs was realized for the first time. ${ }^{2)}$ However, the resulting larvae did not survive for more than two weeks and did not grow into leptocephali. ${ }^{3}$

In previous studies, attempts to induce maturation were carried out using silver eels in most cases. However, silver eels are not easily obtained at present. Therefore, cultivated eels have been used for artificial maturation in some studies, but the results were more variable when compared with those from silver eels. ${ }^{4)}$ More recently, eels feminized with estradiol- $17 \beta$ have also been used for artificial maturation. ${ }^{5)}$ Although these three groups of eels show different responses to SPH, little is known about the extent and the

\footnotetext{
' Corresponding author: Center of Marine Biotechnology, University of Maryland Biotechnology Institute, Baltimore, MD 21202, USA.

E-mail: ijiri@umbi.umd.edu
} 
causes of this variation amongst them at present. In this study, the response to SPH treatment was examined in cultivated, feminized, and silver female eels and related to the developmental stage of the ovary before commencement of treatment.

\section{Materials and Methods}

\section{Fish}

In this study, three groups of Japanese eels were used for induction of artificial maturation. Cultivated female eels which had been reared for five years (body weight 300$900 \mathrm{~g}, n=81$ ) were purchased from a commercial eel supplier (cultivated eel). Glass eels from commercial eel supplier were feminized by feeding them estradiol-17 $\beta$ (10 $\mathrm{mg}$ per $\mathrm{kg}$ pellet) for one month, ${ }^{5,6)}$ and then cultivated for an additional two and a half years until used for experimentation (body weight $350-1050 \mathrm{~g}, n=81$, feminized eel). Silver eels (body weight $300-1100 \mathrm{~g}, n=32$ ) were caught in Hiranuma Lake in Aomori Prefecture (Japan) during the natural spawning migration (silver eel). All group of eels were gradually acclimatized to seawater within two weeks just before the beginning of the experiments, and were kept in $3 \mathrm{~m}^{3}$ recirculating seawater tanks at $20^{\circ} \mathrm{C}$. They were stored throughout the experimental period because they would not feed.

\section{Experiment}

From October to February, eels received weekly intramuscular injections of SPH suspended in eel Ringer ( $\mathrm{NaCl} 3.0 \mathrm{mM}, \mathrm{KCl} 3.0 \mathrm{mM}, \mathrm{MgCl}_{2} 3.5 \mathrm{mM}, \mathrm{CaCl}_{2} 5.0 \mathrm{mM}$, HEPES $10 \mathrm{~mm}, \mathrm{pH} 7.4$ ) or they received Ringer only (control group). Cultivated and silver eels were injected with SPH at a low dose of $20 \mu \mathrm{g}$ per $\mathrm{g}$ body weight (BW), whereas feminized eels were injected at the low dose or a high dose of $40 \mu \mathrm{g}$ per $\mathrm{g} \mathrm{BW}$. Eels were sampled before and throughout the experimental period. Following terminal anaesthesia in $0.1 \%$ aminobenzoate followed by decapitation, the ovaries were dissected and the gonadosomatic index (GSI; weight of ovaries as percentage of total body weight) was calculated. Ovarian follicles were isolated with forceps in ice-cold eel Ringer and both vertical and horizontal diameters of one hundred randomly selected follicles over $50 \mu \mathrm{m}$ were measured using a Profile Projector (Nikon, Tokyo). The size of the largest group of follicles were caluculated by averaging the diameters of the 20 largest means in the sample. The developmental stage of the oocytes was also confirmed by histological analysis. From some eels, a small part of the ovary was collected by abdominal surgery just prior to SPH injection, and the follicle diameters were determined. In addition, some silver and feminized eels whose oocytes had reached the germinal vesicle migration stage were injected intramuscularly with $17 \alpha, 20 \beta$-dihydroxy-4-pregnen-3-one $(17 \alpha, 20 \beta$ DHP; $1 \mu \mathrm{g}$ per $\mathrm{g} \mathrm{BW}$ ) dissolved in ethanol and diluted $50 \%$ with eel Ringer in order to induce ovulation.

\section{Results}

Developmental Stage of the Ovary in Pretreatment Controls

Figure 1 shows the GSI and follicle diameter in relation
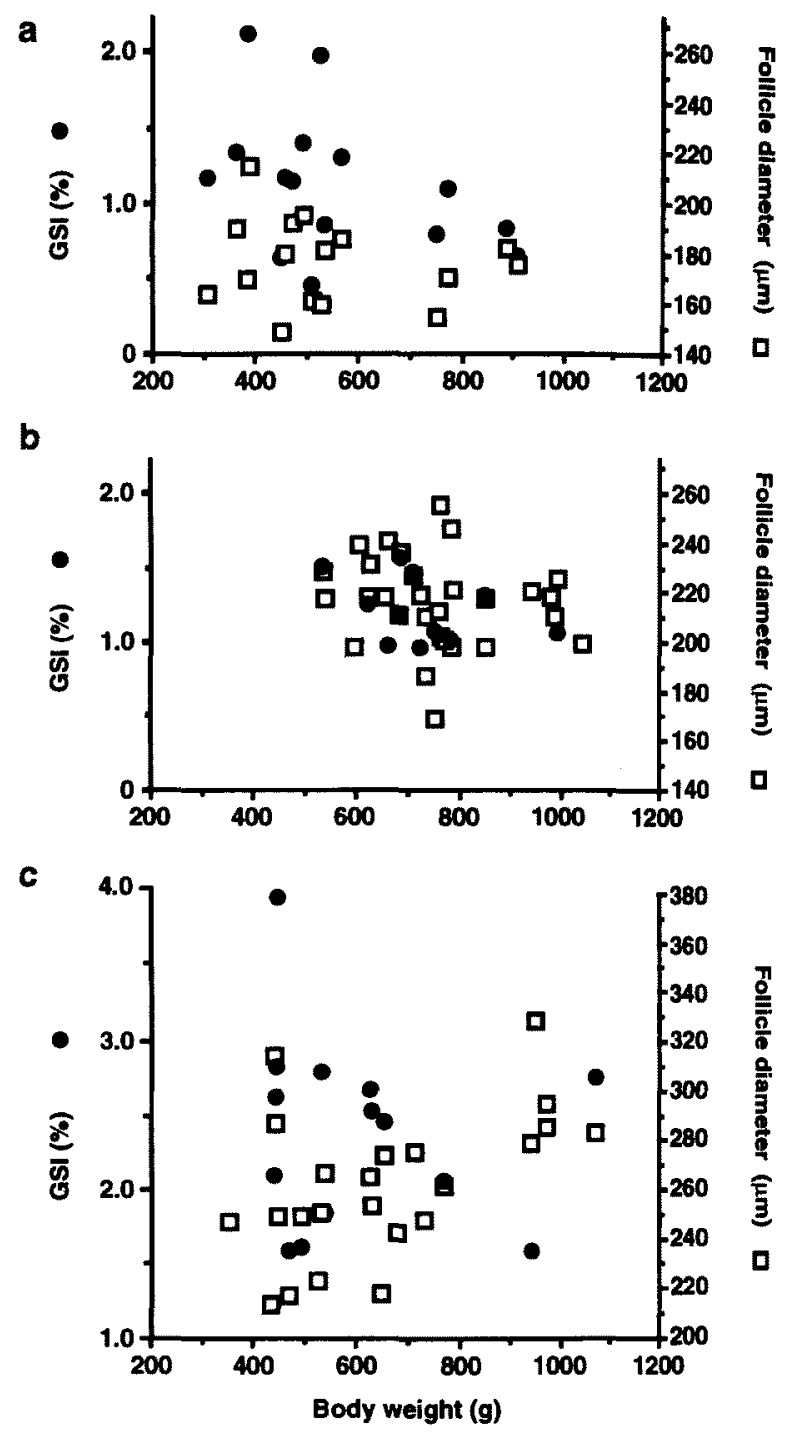

Fig. 1. Relationship between body weight and GSI or average diameter of the largest group of follicles before SPH treatment (a) in cultivated eels, (b) feminized eels, (c) and silver eels.

to the body weight of untreated individual eels, while the frequency distribution of follicle diameters is presented in figure 2. The GSI of some eels could not be calculated, as follicles were collected by surgery without sacrifice. The GSI of cultivated eels prior to SPH injection averaged $1.13 \pm 0.12 \%$ and ranged from $0.46-2.12 \%(n=15$; Fig. 1a). The follicle diameter averaged $176.6 \pm 4.0 \mu \mathrm{m}$ and ranged from 149 to $215 \mu \mathrm{m}$ ( $n=16$; Fig. $2 \mathrm{a}$ ). Developing oocytes from most cultivated eels were generally in the oil droplet stage. In initial feminized eels, the GSI averaged $1.18 \pm 0.06 \%$ and ranged from $0.96-1.57 \%(n=13$; Fig. 1b), while follicle diameters measured $216.6 \pm 3.5 \mu \mathrm{m}$ (range 169-255 $\mu \mathrm{m} ; n=29$; Fig. 2b). Developing oocytes in feminized eels were in the oil droplet or early vitellogenic stage. In silver eels, the GSI was significantly higher than that of the previous groups $(2.39 \pm 0.18 \%$; ANOVA; $F(2$, $39)=29.88, p<0.001$ ), ranging from $1.59-3.98 \%$. This coincided with increased follicle diameters, up to $329 \mu \mathrm{m}$ in size (mean $262.2 \pm 6.3 \mu \mathrm{m} ; n=23$; Fig. 2c). Oocytes of 

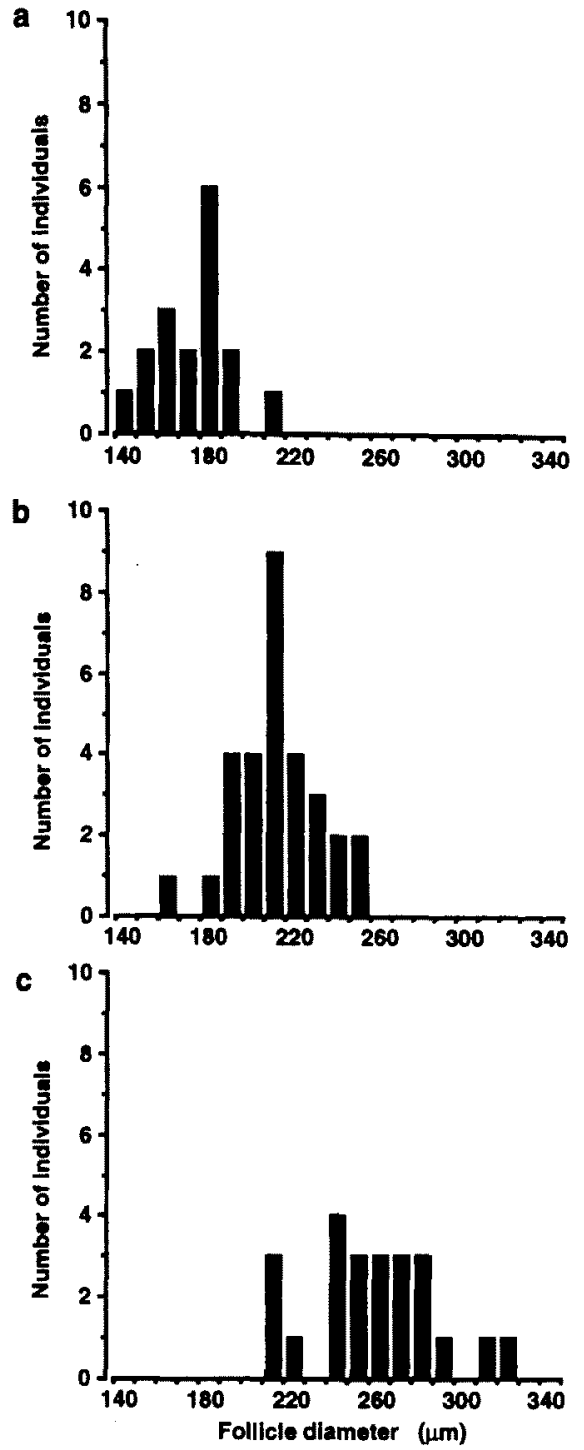

Fig. 2. Frequency distribution of the average diameter of the largest group of follicles (follicle diameter) before SPH injection in (a) cultivated eels, (b) feminized eels, (c) and silver eels.

silver females were predominantly in the early vitellogenic stage.

Eels used in our experiments ranged widely in body weight. Significant correlation was observed between body weight and follicle diameter in silver eels only $(r=0.504$; $p=0.013$ ).

\section{Changes in GSI and Follicle Diameters of Low-dose Treat- ed Eels}

Changes in GSI during low-dose SPH injections (20 $\mu \mathrm{g} / \mathrm{g}-\mathrm{BW}$ ) are presented in figure 3 . Some silver eels whose oocytes reached the migratory nucleus stage were induced to ovulate by injection of $17 \alpha, 20 \beta$-DHP, after which the resulting eggs were used for fertilization. The GSI of these eels could not be calculated exactly, and hence, are plotted separately above the broken line in figure $3 \mathrm{c}$. Germinal visicle migration and hydration were initiated in follicles over $700 \mu \mathrm{m}$ in diameter (final maturational stage of oocyte). a

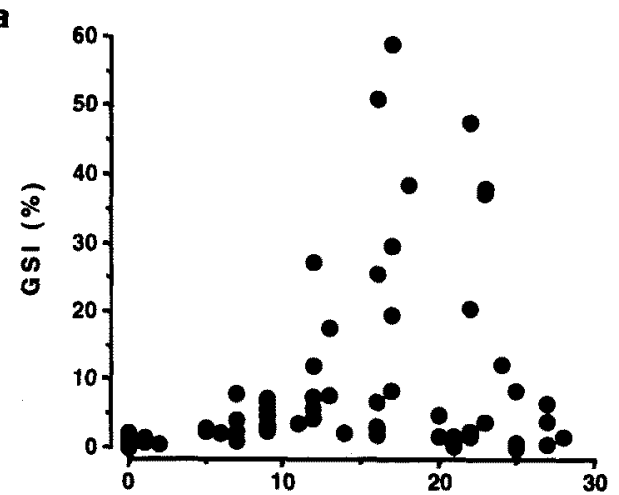

b
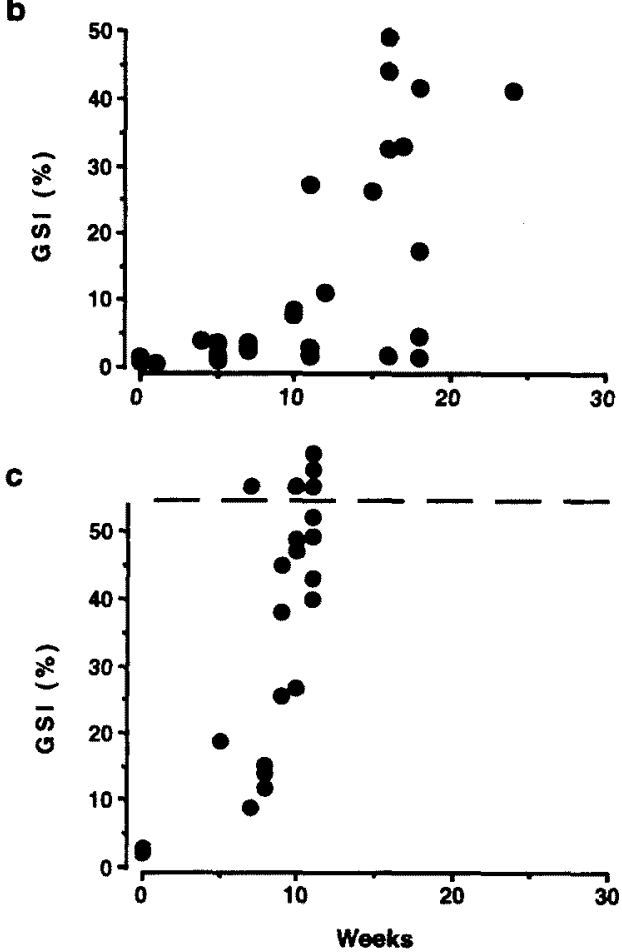

Fig. 3. Changes in GSI during low dose-SPH treatment (a) in cultivated eels, (b) feminized eels, (c) and silver eels.

Individuals plotted above the broken line reached the final maturational phase but GSIs could not be calculated, as these eels were induced to ovulate by $17 \alpha, 20 \beta$-DHP.

The germinal vesicle reached the periphery of the oocyte in follicles of about $850-900 \mu \mathrm{m}$ diameter. Eels with follicles over $700 \mu \mathrm{m}$ in diameter were defined as the final maturational phase. Oocytes entered the migratory nucleus stage when GSIs reached values over about $20 \%$. Therefore, eels whose GSIs were over $20 \%$ were assumed to be in the final maturational phase.

In all groups, eels could be induced artificially to the final maturational phase. The ovarian follicles from silver eels were readily induced to enter the final maturational phase after, on average, 10.2 weeks (range 8-11 weeks; Fig. 3c). Hormonal injections of feminized eels and cultivated eels reached the final maturational phase more slowly (averaging 16.6 and ranging from 11-24 weeks, and averaging 18.6 and ranging from 12-23 weeks, respectively; Fig. 3a, b). 
a

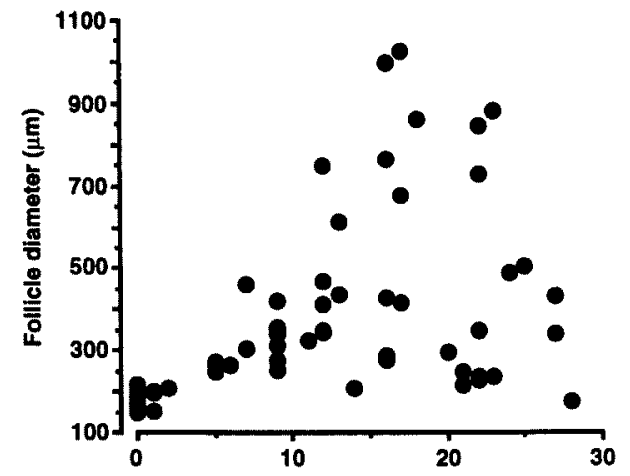

b

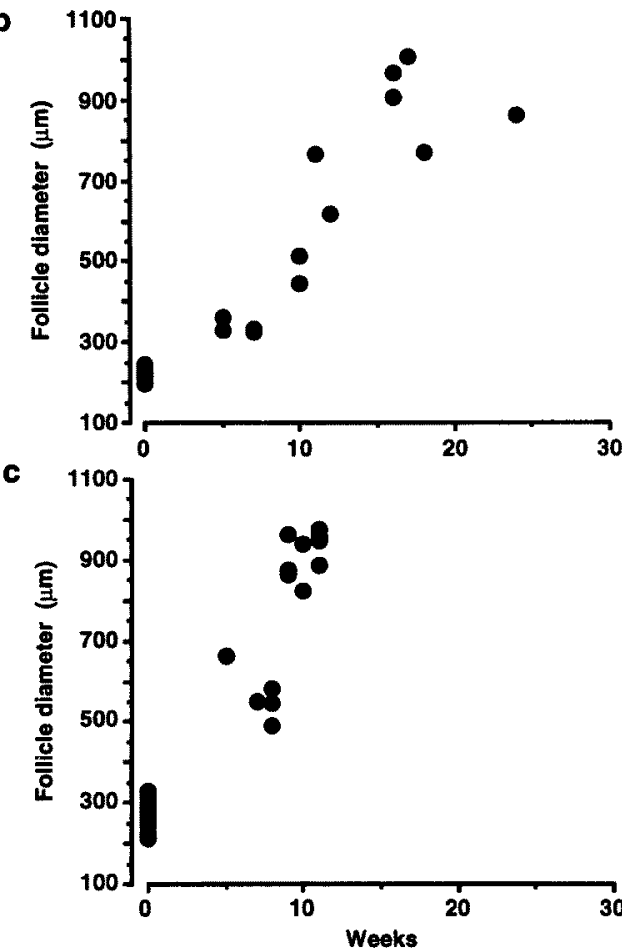

Fig. 4. Changes in average diameter of the largest group of follicles during SPH treatment ( $20 \mu \mathrm{g} / \mathrm{g}-\mathrm{BW})$ in (a) cultivated eels, (b) feminized eels, (c) and silver eels.

Although all silver eels were induced to enter the final maturational phase, SPH injections over 25 weeks did not induce vitellogenic growth of ovarian follicles to the final maturational stage in all cultivated eels and feminized eels. It is difficult to calculate the exact ratio of eels whose follicles reached the final maturational stage, as the response to hormone treatment in fish sacrificed early in the experiment could not be ascertained. The following criteria was employed: using responding eels only, the mean time (MT) required to reach the final maturational phase was calculated. In addition, the ratio of eels that reached the final maturational phase was determined among eels that survived the duration of the experiment. The resulting ratio was highest in silver eels (100\%; MT=10 weeks). Feminized eels also showed a high ratio $(64 \% ; \mathrm{MT}=15$ weeks). Whereas only $29 \%$ of cultivated eels (MT $=15$ weeks) were induced to enter the final maturational phase.

Changes in follicle diameter during SPH treatment positively correlated with changes in GSI (Fig. 4; cultivated
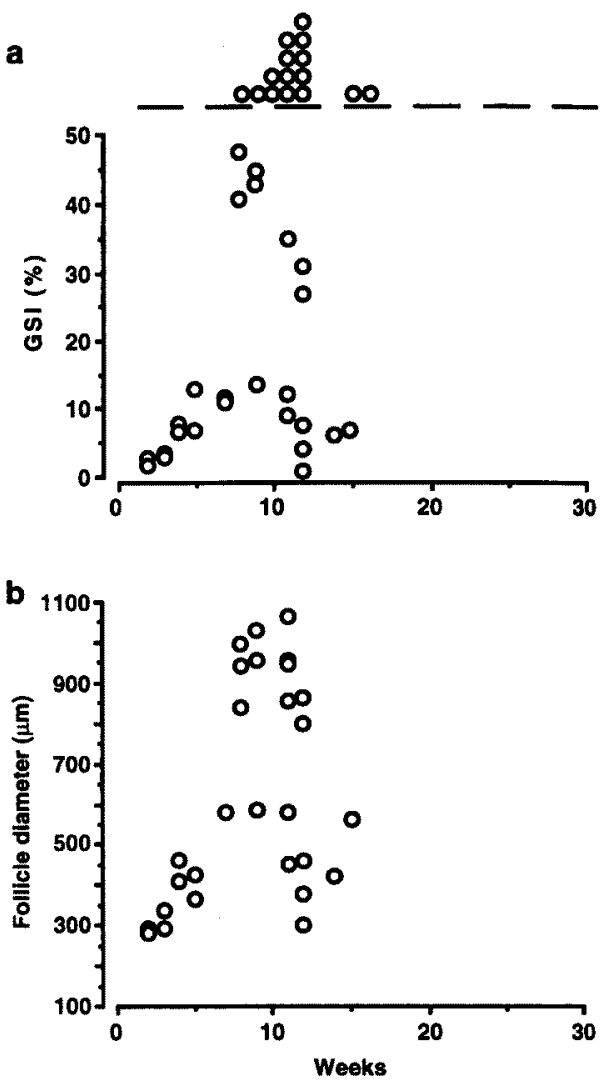

Fig. 5. Changes in (a) GSI and (b) averaged diameter of the largest group of follicles during high dose-SPH treatment $(40 \mu \mathrm{g} / \mathrm{g}-\mathrm{BW})$ in feminized eels.

Individuals plotted above the broken line reached the final maturational phase but GSIs could not be calculated, as these eels were induced to ovulate by $17 \alpha, 20 \beta$-DHP.

eel: $r=0.929, n=70, p<0.0001$; feminized eel: $r=0.952$, $n=22, p<0.0001$; silver eel: $r=0.904, n=18, p<0.0001$ ). In control groups of eels injected weekly with eel Ringer only, GSI and follicle diameter did not increase compared with initial controls (data not shown).

Changes in GSI and Follicle Diameters of High-dose Treated Feminized Eels

A group of feminized eels was subjected to treatment with a high dose of SPH $(40 \mu \mathrm{g} / \mathrm{g} \mathrm{BW})$. Eels induced to ovulate by $17 \alpha, 20 \beta$-DHP have been plotted separately above a broken line, as in figure 3c (Fig. 5). Ovarian follicles of high-dose treated feminized eels were induced to enter the final maturational stage after, on average, 10.9 weeks of treatment, within a range of 8-16 injections (Fig. 5a). The ratio of eels induced to enter the final maturational phase was $71 \%(\mathrm{MT}=10$ weeks). Changes in follicle diameters during SPH treatment again reflected changes in GSI, yielding a significant positive correlation $(r=0.959$, $n=28, p<0.0001$; Fig. 5b).

Relationship Between Basal Ovarian Follicle Diameters and Responsiveness to High-dose SPH Treatment in Feminized Eels

The relationship between the follicle diameter in 
Table 1. Relationship between follicle diameter and the matuational after SPH injection

\begin{tabular}{|c|c|c|c|c|}
\hline Individual Number & $\begin{array}{l}\text { Pretreatment } \\
\text { follicle diameter } \\
\qquad(\mu \mathrm{m})\end{array}$ & $\begin{array}{l}\text { \# of SPH } \\
\text { injections } \\
(n)\end{array}$ & $\begin{array}{l}\text { Developmental stage } \\
\text { after injections }\end{array}$ & $\begin{array}{l}\text { Follicle diameter } \\
\text { after } n \text { injections } \\
\qquad(\mu \mathrm{m})\end{array}$ \\
\hline \multicolumn{5}{|l|}{ Mature group } \\
\hline 1 & 254 & 9 & Migratory nucleus & 1026 \\
\hline 2 & 248 & 8 & Migratory nucleus & 996 \\
\hline 3 & 243 & 8 & Migratory nucleus & 943 \\
\hline 4 & 221 & 8 & Migratory nucleus & 753 \\
\hline 5 & 218 & 8 & Migratory nucleus & 856 \\
\hline 6 & 212 & 9 & Migratory nucleus & - \\
\hline 7 & 210 & 9 & Migratory nucleus & - \\
\hline 8 & 199 & 10 & Migratory nucleus & - \\
\hline 9 & 186 & 8 & Late-vitellogenic & 659 \\
\hline \multicolumn{5}{|l|}{ Immature group } \\
\hline 10 & 253 & 12 & Mid-vitellogenic & 458 \\
\hline 11 & 238 & 15 & Mid-vitellogenic & 561 \\
\hline
\end{tabular}

feminized eels just prior to and after SPH treatment, and the time required to reach the final maturational phase, is shown in Table 1. Follicle diameters in pretreatment animals were calculated from ovaries by surgeries taken just prior to SPH injection, while follicular diameter of post-treatment animals were determined following sacrifice. The post-treatment diameters were not measured in eels 6,7 and 8 because these eels were induced to ovulate by injection of $17 \alpha, 20 \beta$-DHP and resulting eggs were used for fertilization experiments.

Two groups of eels appeared following SPH treatment, i.e., a mature group and an immature group. In the mature group, follicle diameters before treatment ranged from 199-254 $\mu \mathrm{m}$; a distinct relationship between follicle diameter and the required time to reach the final maturational phase was not observed. Eel number nine did not reach the final maturational phase after $8 \mathrm{SPH}$ injections. However, this eel was included in the mature group because its ovary seemed to be developing, judged by weekly increases of its BW. In the immature group, which did not reach the migratory nucleus stage after more than ten SPH injections, the initial follicle diameters ranged from 200 $253 \mu \mathrm{m}$. No difference in follicle diameter prior to SPH injection was observed between the mature group and immature group (Student's $t$-test; $p=0.58$ ).

\section{Discussion}

The developmental stages of oocytes just prior to SPH injection varied widely among cultivated eels, feminized eels, and silver eels. Silver eels at the onset of the spawning migration had the most developed oocytes, which were in early vitellogenesis, while GSI values ranged from 1.6$4.0 \%$. At the onset of the spawning migration, GSI ranges from about $1-2 \%$ in the European eel Anguilla anguilla (with the majority of oocytes in oil droplet stage), ${ }^{1)}$ from about $2-4 \%$ in the shortfinned eel $A$. australis, and from about $5-10 \%$ (with the majority of oocytes in early to midvitellogenic growth phase) in the longfinned eel $A$. dieffenbachii. $^{7}$ ) The developmental stage of oocytes from the Japanese eel was intermediate among these species. This may be a reflection of the intermediate distance to the spawning grounds of the Japanese eel. ${ }^{8-10)}$
The average GSI of feminized eels was lower than that of silver eels, and the oocytes were less developed (oil droplet or early vitellogenic stage). In spite of similar GSIs in feminized and cultivated females, oocytes from feminized eels were more developed than those from cultivated eels, even though cultivated eels were two and a half years older than feminized eels. This finding suggests that estradiol-17 $\beta$ treatment of glass eels influences not only feminization of eels, but also subsequent ovarian development. There are reports that estradiol-17 $\beta$ affects gonadotropin synthesis and secretion in the pituitary of European eels. ${ }^{11)}$ Estradiol-17 $\beta$ treatment at the glass eel stage may therefore advance subsequent ovarian development via gonadotropin secretion, induction of vitellogenesis, and/or other factors.

Among all groups, body weight and pretreatment follicle diameter significantly correlate in silver eels only. This is the first report of such a correlation in Japanese eels at the silver stage. In contrast, body weight and GSI did not show a significant correlation in any group, indicating that follicle diameter may be a more reliable criterium for staging silver eels than GSI.

The number of SPH injections needed to reach the final maturational phase seemed to correlate well with the developmental stage of oocytes before treatment began. In low-dose treated fish, the ovarian follicles of silver eels were the quickest to progress to the maturational phase when induced by SPH. These observations suggest that the developmental stage of the oocytes prior to treatment is directly correlated to the responsiveness of the oocytes to reach the final maturational phase.

All silver eels could be induced to reach the maturational phase, but this could not be achieved among feminized and cultivated eels. This may again be related to the fact that silver eels have the most developed oocytes before SPH treatment commenced. Similarly, a lesser degree of sexual development in feminized eels and cultivated eels may explain why not all eels could be induced to the final maturational phase. Indeed, only $29 \%$ of cultivated eels entered the final maturational phase. Since cultivated eels displayed a wide range of follicle diameters among pretreated individuals, only eels with the most developed oocytes would have entered the final maturational phase fol- 
lowing SPH injections. Feminized eels were induced to the final maturational phase at a higher ratio than cultivated eels. These results clearly indicate that feminization of glass eels is a useful method for supplying eels for artificial maturation studies.

Feminized eels were also subjected to high dose-treatment of SPH to examine the effects of dose of SPH on the ratio and the required time to induce eels to the final maturational phase. High-dose treated feminized eels reached the final maturational phase in almost the same time span as silver eels, and at a higher ratio than low-dose treated feminized eels. These differences in responsiveness to SPH probably depend on the long-lasting effect of SPH on oocyte development when injected at the high dose. To investigate the relationship between the developmental stage of follicles before and after SPH injections, a small part of the ovary was collected by surgery just before SPH treatment began, and the follicle diameters were calculated. A distinct correlation between follicle diameter just prior to SPH treatment and the number of injections required until the final maturational stage was not observed. However, it was shown that eels whose follicle diameter was over about $180 \mu \mathrm{m}$ could be induced to the final maturational phase. This finding indicates that the majority of feminized eels can probably be induced to the final maturational phase, because the follicle diameter of most initial feminized eels falls within that range. However, significant differences were not found between mature and immature groups of eels regarding follicle diameter before SPH injection. Eels that failed to mature had oocytes before treatment which were large enough to expect successfull induction of the final maturational phase. Therefore, the diameter of the oocyte (i.e. amount of vitellogenic inclusion) before SPH injection of feminized eels is not likely to be responsible for whether the eel can be induced to enter the final maturational phase or not. Instead, other factors, for example immunoreaction to SPH, reduction of GTH receptors in the follicle and/or handling stress of injections are more likely causes. Sato et al. recognized that ovarian development was not induced in eels which had antibodies against exogenously administered salmon GTH in the plasma, though their method of artificial maturation was different from that in the present study. ${ }^{12}$

Cultivated eels require more SPH injections to reach the final maturational phase than silver eels and feminized eels. Such long-term treatment could conceivably cause immunoreaction to SPH at a higher ratio and/or result in more stress than in shorter treated groups. As a result, many cultivated eels with the least developed oocytes could not enter the final maturational phase. Moreover, we observed that oocytes in the migratory nucleus stage, obtained from females that had received relatively many SPH injections, tended to show abnormal development, for example lipid coalescence or clearing of the ooplasm in oocytes, compared to oocytes from silver eels and highdose treated feminized eels (data not shown). Therefore, it may be concluded that eels should be induced to mature in a relatively short time of SPH treatment, say within two to three months, for artificial maturation to be successful.

In conclusion, the developmental stages of ovaries from three groups of untreated eels were most advanced in the following order; silver eels, feminized eels, and cultivated

\begin{tabular}{lcccccc}
\hline & \multicolumn{2}{c}{ Pretreatment } & & \multicolumn{2}{c}{ Over 20\% in GSI } \\
\cline { 3 - 4 } \cline { 6 - 7 } & $\begin{array}{c}\text { SPH } \\
\text { treatment }\end{array}$ & GSI & $\begin{array}{c}\text { Follicle } \\
\text { diameter }\end{array}$ & & $\begin{array}{c}\text { Average \# } \\
\text { injections needed }\end{array}$ & $\begin{array}{c}\text { Rate to be } \\
\text { induced } \\
\text { to mature }\end{array}$ \\
\hline Cultivated eel & $20 \mu \mathrm{g} / \mathrm{g}$ & $1.1 \%$ & $177 \mu \mathrm{m}$ & & 18.6 times & $29 \%$ \\
Feminized eel & $20 \mu \mathrm{g} / \mathrm{g}$ & $1.2 \%$ & $217 \mu \mathrm{m}$ & & 16.6 times & $64 \%$ \\
& $40 \mu \mathrm{g} / \mathrm{g}$ & & & & 10.9 times & $71 \%$ \\
Silver cel & $20 \mu \mathrm{g} / \mathrm{g}$ & $2.4 \%$ & $262 \mu \mathrm{m}$ & & 10.2 times & $100 \%$ \\
\hline
\end{tabular}

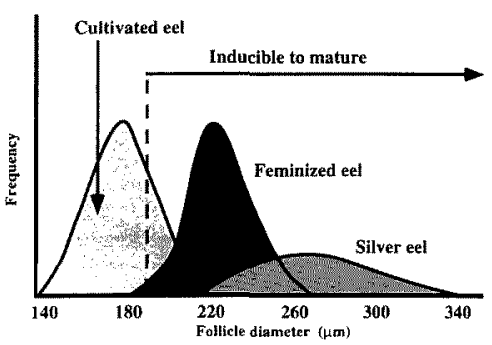

Fig. 6. A schematic representation of distribution of follicle diameter and responses of ovarian development to SPH among each group of eels.

A broken line represents the minimum diameter of follicle which could be artificially induced to mature to the final maturational.

eels. Estradiol-17 $\beta$ treatment of glass eels perhaps affects not only feminization of eels but also subsequent ovarian development. The developmental stage of the ovary probably directly influences the success rate of artificial maturation and the time required to reach the final maturational phase. Eels whose follicle diameter was over about $180 \mu \mathrm{m}$ may be induced to the final maturational phase (summarized in Fig. 6). Thus, silver eels are the most preferable for artificial maturation. However, those eels are difficult to obtain at present. Therefore, it can be concluded that feminized eels have the best potential for use in artificial maturation studies.

Acknowledgments The authors are grateful to Dr. Mark Lokman (Hokkaido University) for critical reading of the manuscript. Thanks are also due to Hiromi Okumura, Ikumi Nakamura, Yukinori Kazeto, Fumihiro Saeki, Kensei Kyoku, Yusuke Okawa, Yuka Chida, Toshiharu Yanagawa and Yuichi Ozaki (Hokkaido University) for their valuable as sistance. This research was supported in part by a grant from the Fisheries Agency and by a Scientific Research grant from the Ministry of Education, Science, Sports and Culture.

\section{References}

1) A. F. Bruun, A. M. Hemmingsen, and E. Møller-Christensen: Attempts to induce experimentally maturation of the gonads of the European eel, Anguilla anguilla L. Acta endocrinol., 2, 212-226 (1949).

2) K. Yamamoto and K. Yamauchi: Sexual maturation of Japanese eel and production of eel larvae in the aquarium. Nature, 251, 220-222 (1985).

3) K. Yamauchi, M. Nakamura, H. Takahashi, and K. Takano: Cultivation of larvae of Japanese eel. Nature, 263, 412 (1976).

4) S. Ijiri, Y. Kazeto, N. Takeda, H. Chiba, S. Adachi, and K. Yamauchi: Changes in serum steroid hormones and steroidogenic ability of ovarian follicles during artificial maturation of cultivated Japanese eel, Anguilla japonica. Aquaculture, 135, 3-16 (1995).

5) H. Tachiki and T. Nakagawa: Induction of spawning in female cultured eel Anguilla japonica. Bull. Aichi. Fish. Res. Int., 1, 79-80 (1993) (in Japanese).

6) H. Tachiki, T. Nakagawa, K. Tamura, and K. Hirose: Effects of oral administration of estradiol- $17 \beta$ to young on gonadal sex and 
growth of Japanese eel Anguilla japonica. Suisanzousyoku, 45, 6166 (1997) (in Japanese).

7) P. R. Todd: Morphometric changes, gonad histology, and fecundity estimated in migrating New Zealand freshwater eels (Anguilla spp.). NZ J. Mar. Freshw. Res., 15, 155-170 (1981).

8) K. Tsukamoto: Discovery of the spawning area for Japanese eel. $\mathrm{Na}$ ture, 356, 789-791 (1992).

9) J. Schmidt: The breeding places of the eel. Phil. Trans. Royal Soc. London, B211, 179-208 (1922).

10) D. J. Jellyman: Review of the marine life history of Australasian temperate species of Anguilla. American Fisheries Society Symposium, 1, 276-285 (1987).

11) S. Dufour, N. Le Belle, and Y. A. Fontaine: Effects of steroid hormones on pituitary immunoreactive gonadotropin in European freshwater eel, Anguilla anguilla L. Gen. Comp. Endocrinol., 52, 190-197 (1983).

12) N. Sato, I. Kawazoe, Y. Suzuki, and K. Aida: Use of an emulsion prepared with lipophilized gelatin for the induction of ovarian maturation in the Japanese eel Auguilla japonica. Fisheries Sci., 62, 815820 (1996). 